Article

\title{
Endo-S-c-di-GMP Analogues-Polymorphism and Binding Studies with Class I Riboswitch
}

\author{
Jie Zhou, David A. Sayre, Jingxin Wang, Nirmal Pahadi and Herman O. Sintim * \\ Department of Chemistry and Biochemistry, University of Maryland, College Park, MD 20742, USA \\ * Author to whom correspondence should be addressed; E-Mail: hsintim@umd.edu; \\ Tel.: +1-301-405-0633; Fax: +1-301-314-9121.
}

Received: 21 September 2012; in revised form: 30 October 2012 / Accepted: 1 November 2012 /

Published: 9 November 2012

\begin{abstract}
C-di-GMP, a cyclic guanine dinucleotide, has been shown to regulate biofilm formation as well as virulence gene expression in a variety of bacteria. Analogues of c-di-GMP have the potential to be used as chemical probes to study c-di-GMP signaling and could even become drug leads for the development of anti-biofilm compounds. Herein we report the synthesis and biophysical studies of a series of c-di-GMP analogues, which have both phosphate and sugar moieties simultaneously modified (called endo-S-c-di-GMP analogues). We used computational methods to predict the relative orientation of the guanine nucleobases in c-di-GMP and analogues. DOSY NMR of the endo-S-c-di-GMP series showed that the polymorphism of c-di-GMP can be tuned with conservative modifications to the phosphate and sugar moieties (conformational steering). Binding studies with Vc2 RNA (a class I c-di-GMP riboswitch) revealed that conservative modifications to the phosphate and 2'-positions of c-di-GMP dramatically affected binding to class I riboswitch.
\end{abstract}

Keywords: c-di-GMP; endo-S-c-di-GMP; polymorphism; G-quadruplex; analogues; DOSY; Vc2 RNA; fluorescence; aptamer

\section{Introduction}

Cyclic diguanylic monophosphate (c-di-GMP) is a second messenger in bacteria and plays a central role in biofilm formation and the regulation of virulence-related factors in many bacteria [1]. C-di-GMP is produced from two guanosine triphosphate (GTP) molecules via diguanylate cyclases 
(DGCs), which contain the common protein domain GGDEF and is further broken down into 5'-phosphoguanylyl-(3'-5')-guanosine (pGpG) by specific phosphodiesterases (PDEs), characterized by the protein domain EAL [2-6]. C-di-GMP is known to bind to I-site of DGCs [7,8], PDEs [9,10], PilZ domain proteins [11-13], transcriptional regulators [14,15] and RNA riboswitches [16,17]. Small molecules that could compete with c-di-GMP for binding to receptors have the potential to inhibit biofilm formation and virulence factors production in bacteria. There are several precedents whereby the modifications of natural nucleotides have produced analogues with interesting biological profiles and some of these analogues could even have clinical utility [18-26]. Therefore, as a starting point to develop small molecules that could potentially be used to disrupt c-di-GMP signaling, a few groups (including ours) have begun investigating the structure-activity relationship of c-di-GMP binding to both proteins and RNA [27-33]. Previously, we showed that a conservative change to one of the phosphodiester "bridging" oxygens in c-di-GMP gave an analogue called endo-S-c-di-GMP (2, see Figure 1), which has a much lower propensity to form aggregates compared to c-di-GMP [27].

Figure 1. Family of dual-modified c-di-GMP analogues synthesized.
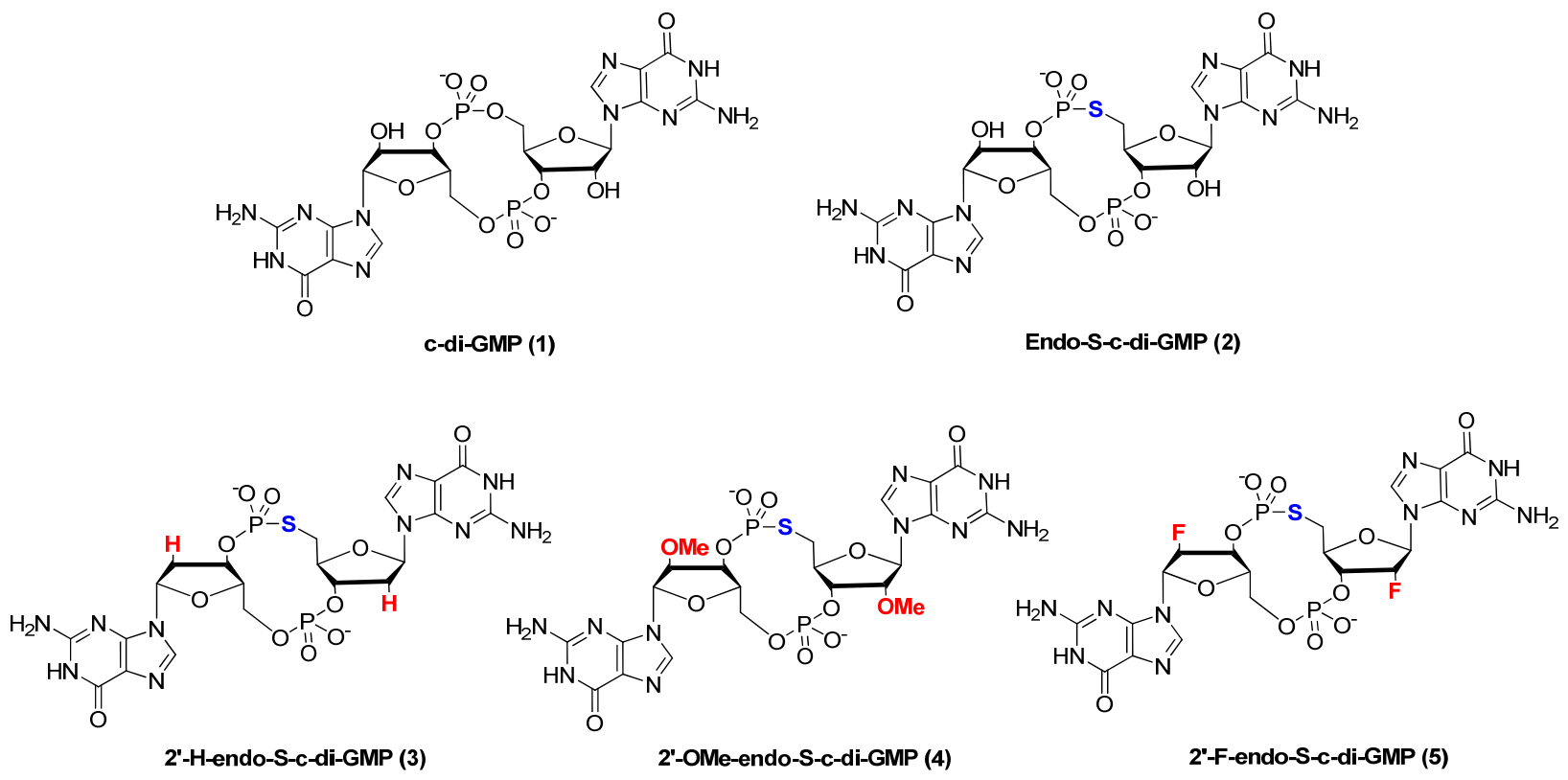

Importantly, endo-S-c-di-GMP could compete with the natural c-di-GMP for binding to RocR, a PDE, but had little affinity for WspR (a DGC) or Alg44 (a PilZ-containing protein). This suggests that modifications to the phosphate moiety of c-di-GMP, at the bridging oxygen position at the phosphodiester moiety could give analogues of c-di-GMP, which could be used to selectively target c-di-GMP receptors. C-di-GMP has also been shown to bind to RNA riboswitches and recent reports suggest that the 2'-modification of c-di-GMP differentially affected binding of these analogues to c-di-GMP riboswitches [17,28,30,33]. We wondered if the simultaneous modification of both the phosphate, at the bridging oxygen position of the phosphodiester moiety, and the 2'-position would lead to another series of c-di-GMP analogues with differential binding profiles. Herein, we describe the synthesis, biophysical characterization and binding to Vc2 RNA of this new class of c-di-GMP analogues, see Figure 1 for structures. 


\section{Results and Discussion}

\subsection{Synthesis of c-di-GMP Analogues}

Endo-S-c-di-GMP analogues 3-5 were easily synthesized on a solid support [34], following the strategy outlined in Scheme 1. Briefly, a guanosine phosphoramidite was coupled to a phosphate CPG and the first nucleotide was sulfurized using commercially available Beaucage reagent. The second coupling was done, also with the same guanosine phosphoramidite, but this time iodine was used for the oxidation step to give an interlinking phosphate. The DMT group was then deprotected, using trichloroacetic acid and the 5'-hydroxyl group was converted into an iodide. The dinucleotide was then cleaved from the solid support with $\mathrm{NH}_{4} \mathrm{OH}$ (28\% in water). This step also cleaved the cyanoethyl protecting group on the phosphate as well as the acetyl group on the exocyclic amine of the guanine. Upon cleavage from the solid support, a cyclization ensued via a $\mathrm{S}_{\mathrm{N}} 2$ displacement of the 5'-iodide with the 3'-phosphorothioate group. The 2'-OTBS group (in compound 2) was then deprotected, using $\mathrm{NEt}_{3} \cdot 3 \mathrm{HF}$.

Scheme 1. Synthesis of endo-S-c-di-GMP analogues (2-5).

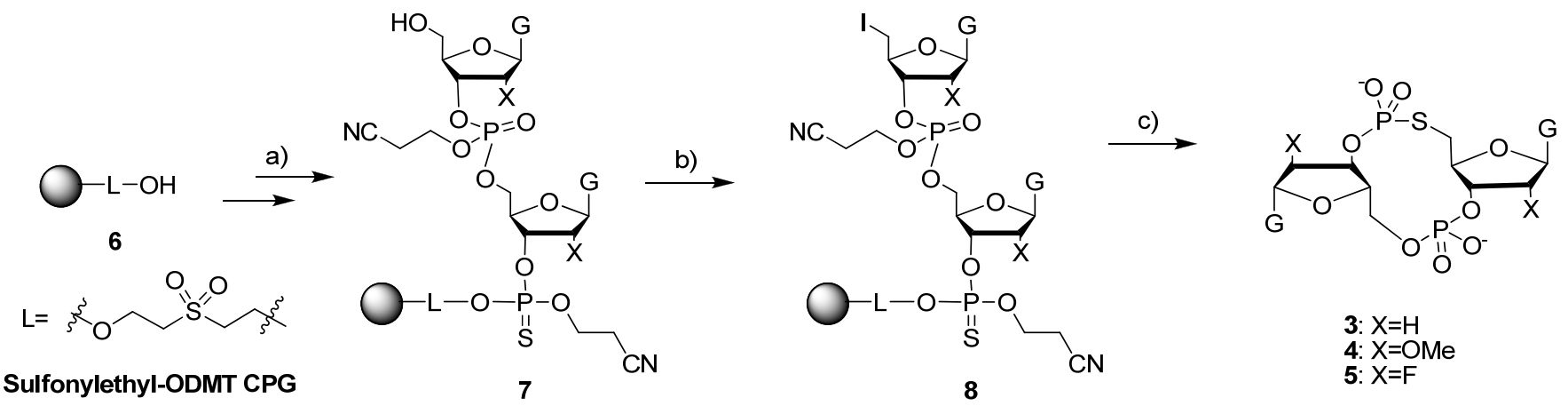

Reagents and conditions: (a) done using a programmed DNA/RNA synthesizer; (b) methyltriphenoxyphosphonium iodide, 2,6-lutidine, anhydrous DMF, rt, $1 \mathrm{~h}$; (c) $28 \% \mathrm{NH}_{4} \mathrm{OH}, 40{ }^{\circ} \mathrm{C}, 12 \mathrm{~h}$.

\subsection{Polymorphism of c-di-GMP Analogues}

Polymorphism of c-di-GMP, which depends on physiological conditions (such as the concentration of cations), is relevant to the biological effect of c-di-GMP because different proteins bind to different conformational or aggregation states of c-di-GMP. For example, c-di-GMP binds to most I-sites of DGCs as a self intercalated dimer [7] whereas for PDEs and some PilZ proteins, c-di-GMP binds to the active site as a monomer in either the open form (whereby the two guanines are relatively far away to each other) [9] or the closed form (whereby the two guanines are relatively close to each other) [12]. Recently Chou et al. further observed that different proteins could bind to different conformers (with different glycosidic bond angles and/or sugar pucker modes) of the open form of c-di-GMP [35]. Thus it is possible to selectively target c-di-GMP receptors with c-di-GMP-like molecules that mainly exist in a particular conformation, which nicely fits into the binding site of an effector protein or RNA.

C-di-GMP (1) at millimolar concentrations and in the presence of potassium cations also forms several polymorphs, including dimers, tetramers and octamers (which contain G-tetrads) [27,36,37]. Interestingly, by replacing one of the bridging oxygens of the phosphodiester units in c-di-GMP with a 
sulfur atom (a conservative modification) to give an analogue that we name endo-S-c-di-GMP (2), the propensity to form G-quadruplex drastically diminishes [27]. We have proposed that one could make a gross prediction for the relative propensity of c-di-GMP analogues to form G-quadruplexes by calculating the relative energies of one of the open conformers (where the two guanines are $13.5 \AA$ apart) to the closed conformer (where the two guanines are $6.8 \AA$ apart) [27]. It would be computationally prohibitive to evaluate all of the energies of all possible conformers of c-di-GMP. To simplify the computational study, the structures computed in this paper were chosen as the closed conformer (anti C3'-endo) or one of the three open conformers (anti C2'-endo) [35]. Following our precedent [27], and using Gaussian 09 software [38] we obtained relative energy differences between the "closed" and "open" conformers of c-di-GMP and each analogue (2-5), see Table 1. The closed conformers of both c-di-GMP (1), endo-S-c-di-GMP (2) and 2'-F-endo-S-c-di-GMP (5) seem to be more stable than the open conformers, whereas for 2'-H-endo-S-c-di-GMP (3) the energies of both conformers are similar. On the other hand, the open conformer of 2'-OMe-endo-S-c-di-GMP (4) appears to be more stable than the closed conformer. We note however that these calculations are simplistic and do not take into account all of the possible c-di-GMP conformers. Additionally this calculation might not have modeled hydration and salt effects very well, so the obtained values have to be interpreted with caution. Nonetheless, the computed data reveals that subtle differences at the phosphate and 2'-position of c-diGMP could drastically affect the conformation of the molecule (conformational steering). Based on our computational study, we expected that the conformational preference for 2 '-F-endo-S-c-di-GMP (5) would be similar to endo-S-c-di-GMP (2) whereas 2'-H-endo-S-c-di-GMP (3) and 2'-OMe-c-di-GMP (4) would behave differently from endo-S-c-di-GMP (2) and might have a lower propensity to form G-quadruplexes, because the closed conformer, which is required for G-quadruplex formation is predicted to be the minor conformer in these analogues.

Table 1. Computed energy difference between "open" and "closed" forms of c-di-GMP (1) and analogues (2-5).

\begin{tabular}{ccc}
\hline & $\boldsymbol{\Delta E}^{\text {sol }}$ (open-closed) $^{\boldsymbol{a}}$ & ratio (open:closed) $^{\boldsymbol{b}}$ \\
\hline c-di-GMP (1) & 1.9 & $1: 25$ \\
endo-S-c-di-GMP (2) & 1.3 & $1: 9$ \\
2'-H-endo-S-c-di-GMP (3) & -0.3 & $2: 1$ \\
2'-OMe-endo-S-c-di-GMP (4) & -2.2 & $39: 1$ \\
2'-F-endo-S-c-di-GMP (5) & 0.5 & $1: 3$ \\
\hline
\end{tabular}

${ }^{a}$ The electronic energy was computed with Gaussian 09 software with HF/6-31G(d) basis set. Solvent effect $\left(\mathrm{H}_{2} \mathrm{O}\right)$ was calculated using Onsager's model in a self-consistent reaction field; ${ }^{b}$ The ratio was determined from the equilibrium constant $K$, obtained fromthe equation $\Delta E=-\mathrm{R} T \ln K(T=298 \mathrm{~K})$.

When c-di-GMP forms G-quadruplexes, each monomer unit exists in the closed conformer [36]. We wondered if the trend seen in our computational study (Table 1) would correlate with the aggregative properties of the various endo-S-c-di-GMP analogues. We used NMR to characterize the aggregates in the absence or presence of potassium. Previously we used DOSY experiment followed by $T_{1} / T_{2}$ relaxation analysis to obtain the diffusion constants of c-di-GMP (1) and endo-S-c-di-GMP (2) [27]. Because an inverse relationship exists between the size of a particle and diffusion rate, the $T_{1} / T_{2}$ 
relaxation analysis can be used to deduce the size of an aggregate, if data for the monomer can be obtained.

NMR data revealed that the propensities of 2'-H-endo-S-c-di-GMP (3) and 2'-OMe-endo-S-c-diGMP (4) to form higher aggregates are lower than for c-di-GMP (1) and endo-S-c-di-GMP (2) (see Figures $2 \mathrm{~b}$ and $3 \mathrm{~b}$, which show that no new peaks appeared when potassium was added to a solution containing these two endo-S-c-di-GMP analogues).

Figure 2. ${ }^{1} \mathrm{H}-\mathrm{NMR}$ stacked spectra of $3.0 \mathrm{mM}$ analogue 3 in $\mathrm{D}_{2} \mathrm{O}$. (a) $3.0 \mathrm{mM} 2$ '-H-endoS-c-di-GMP, $100 \mathrm{mM} \mathrm{KCl,} 60{ }^{\circ} \mathrm{C}$. (b) $3.0 \mathrm{mM}$ 2'-H-endo-S-c-di-GMP, $100 \mathrm{mM} \mathrm{KCl,} 30{ }^{\circ} \mathrm{C}$. (c) $3.0 \mathrm{mM}$ 2'-H-endo-S-c-di-GMP, no metal cation, $30^{\circ} \mathrm{C}$. (d) $3.0 \mathrm{mM}$ 2'-H-endo-S-c-diGMP, $\mathrm{T}_{1} / \mathrm{T}_{2}$ relaxation analysis (from DOSY experiments).

\section{2'-H-endo-S-c-di-GMP (3)}

With $\mathrm{K}^{+}$at $60^{\circ} \mathrm{C}$ $2 a$

\section{2'-H-endo-S-c-di-GMP (3)}

With $\mathrm{K}^{+}$at $30^{\circ} \mathrm{C}$

2b

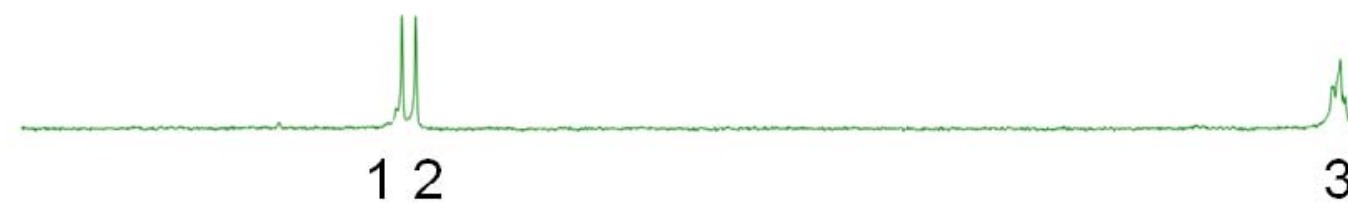

2'-H-endo-S-c-di-GMP (3)

$\mathrm{No} \mathrm{K}^{+}$at $30^{\circ} \mathrm{C}$

2C

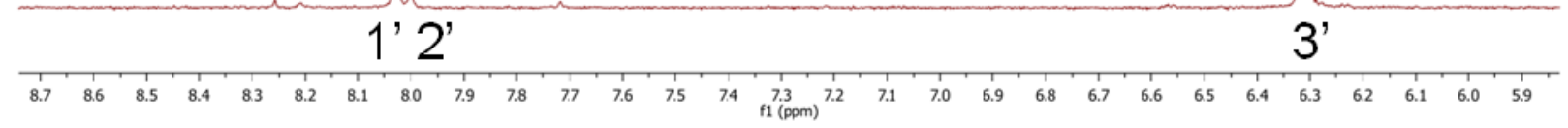

$2 d$

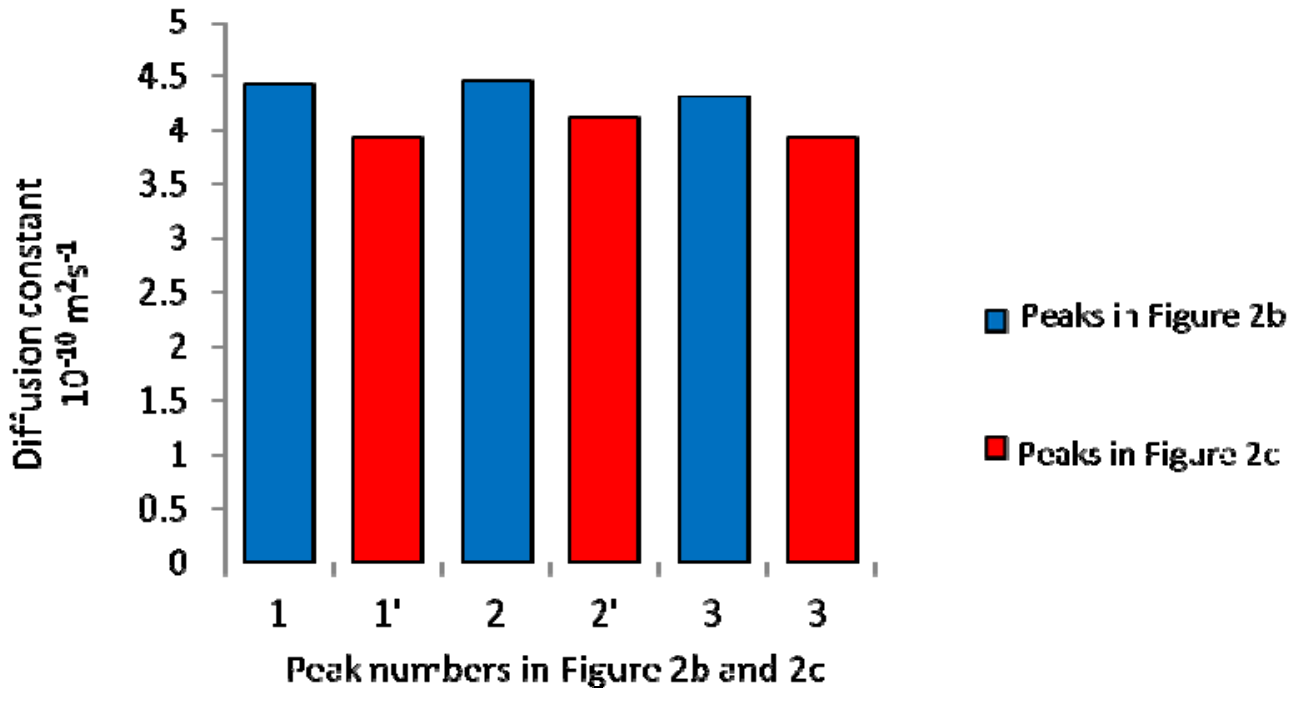


Figure 3. ${ }^{1} \mathrm{H}-\mathrm{NMR}$ stacked spectra of $3.0 \mathrm{mM}$ analogue 4 in $\mathrm{D}_{2} \mathrm{O}$. (a) $3.0 \mathrm{mM} 2^{\prime}-\mathrm{OMe}-$ endo-S-c-di-GMP, $100 \mathrm{mM} \mathrm{KCl}, 60{ }^{\circ} \mathrm{C}$. (b) $3.0 \mathrm{mM}$ 2'-OMe-endo-S-c-di-GMP, $100 \mathrm{mM}$ $\mathrm{KCl}, 30{ }^{\circ} \mathrm{C}$. (c) $3.0 \mathrm{mM}$ 2'-OMe-endo-S-c-di-GMP, no metal cation, $30^{\circ} \mathrm{C}$. (d) $3.0 \mathrm{mM}$ 2'-OMe-endo-S-c-di-GMP, $\mathrm{T}_{1} / \mathrm{T}_{2}$ relaxation analysis (from DOSY experiments).

2'-OMe-endo-S-c-di-GMP (4)

With $\mathrm{K}^{+}$at $60^{\circ} \mathrm{C}$

$3 a$

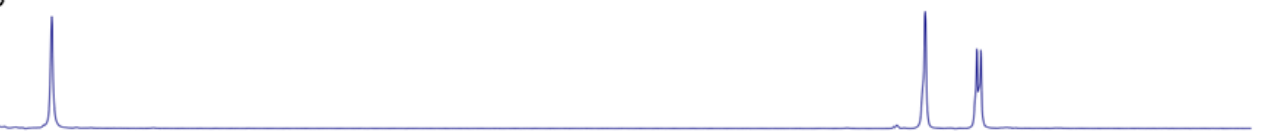

2'-OMe-endo-S-c-di-GMP (4)

With $\mathrm{K}^{+}$at $30^{\circ} \mathrm{C}$

$3 \mathrm{~b}$

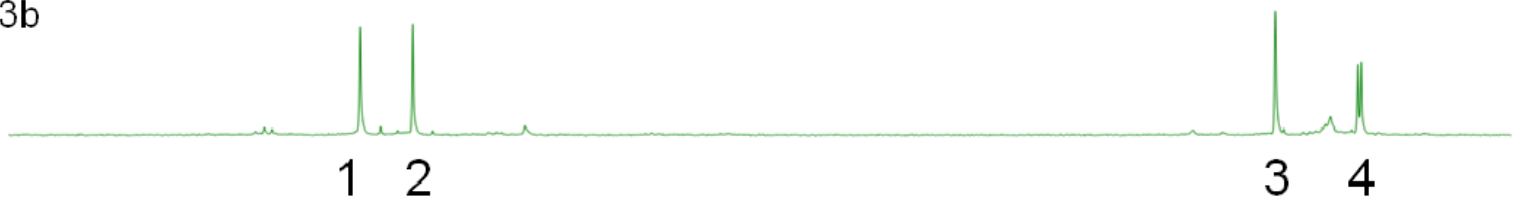

2'-OMe-endo-S-c-di-GMP (4)

$\mathrm{No} \mathrm{K}^{+}$at $30^{\circ} \mathrm{C}$

$3 \mathrm{c}$

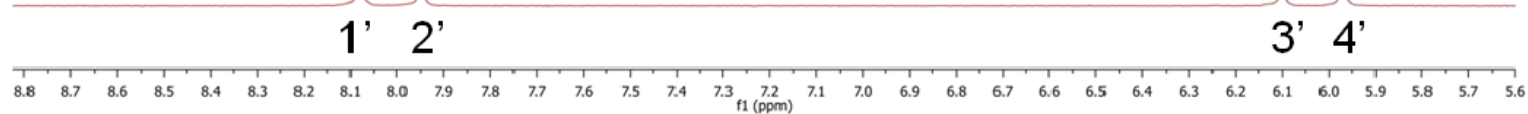

$3 d$

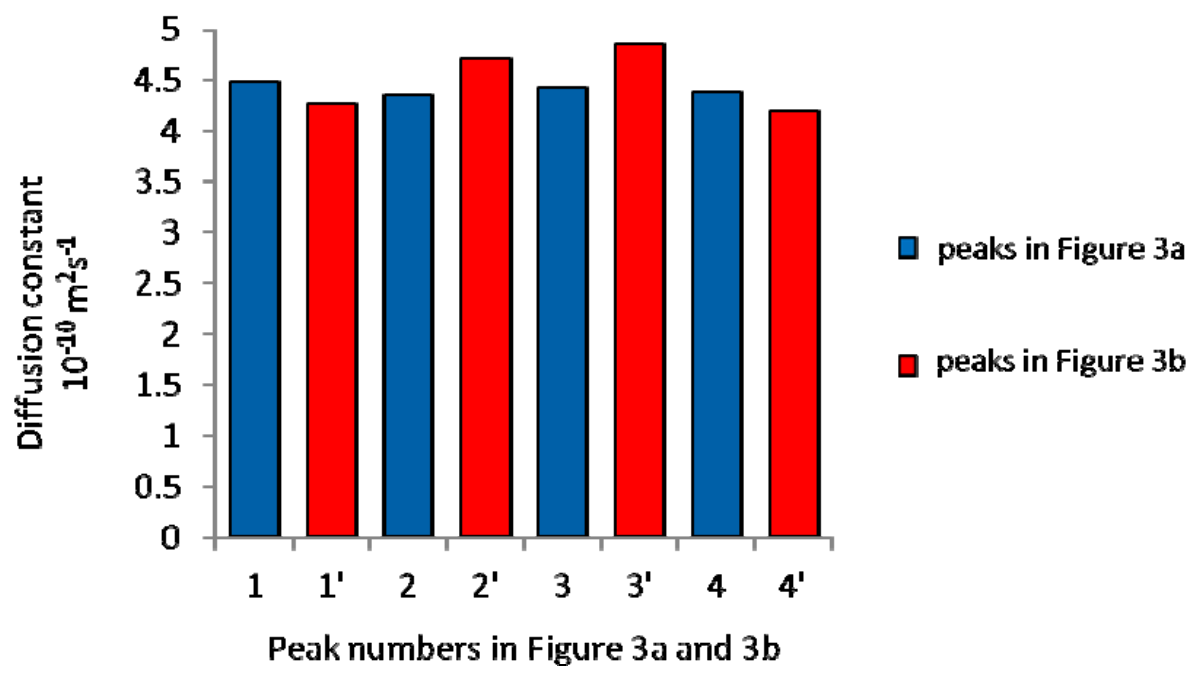

However, 2'-F-endo-S-c-di-GMP (5) formed higher aggregates (octamers) in the presence of potassium cations, see Figure 4. For 2'-F-endo-S-c-di-GMP, the two singlets at 8.05 and $7.92 \mathrm{ppm}$ are assigned to the two guanines $\mathrm{H} 8$ and two sets of doublet at 6.28 and $6.18 \mathrm{ppm}$ are assigned to the anomeric H1' (see Figure 4c). We notice that the line width of the 2'-F-endo-S-c-di-GMP peaks at 8.05 and $7.92 \mathrm{ppm}$ are quite broad at $30{ }^{\circ} \mathrm{C}$ but become narrow when potassium is added. Grzesiek and co-workers have shown that monomeric c-di-GMP is in equilibrium with dimeric form and it is plausible that the line broadening in the absence of potassium is the effect of the dynamic process rising from the monomer-dimer exchange [39]. 
Figure 4. ${ }^{1} \mathrm{H}-\mathrm{NMR}$ stacked spectra of $3.0 \mathrm{mM}$ analogue 5 in $\mathrm{D}_{2} \mathrm{O}$. (a) $3.0 \mathrm{mM}$ 2'-F-endo-Sc-di-GMP, $100 \mathrm{mM} \mathrm{KCl}, 60{ }^{\circ} \mathrm{C}$. (b) $3.0 \mathrm{mM}$ 2'-F-endo-S-c-di-GMP, $100 \mathrm{mM} \mathrm{KCl}, 30{ }^{\circ} \mathrm{C}$. (c) $3.0 \mathrm{mM}$ 2'-F-endo-S-c-di-GMP, no metal cation, $30^{\circ} \mathrm{C}$. (d) $3.0 \mathrm{mM}$ 2'-F-endo-S-c-diGMP, $\mathrm{T}_{1} / \mathrm{T}_{2}$ relaxation analysis (from DOSY experiments).
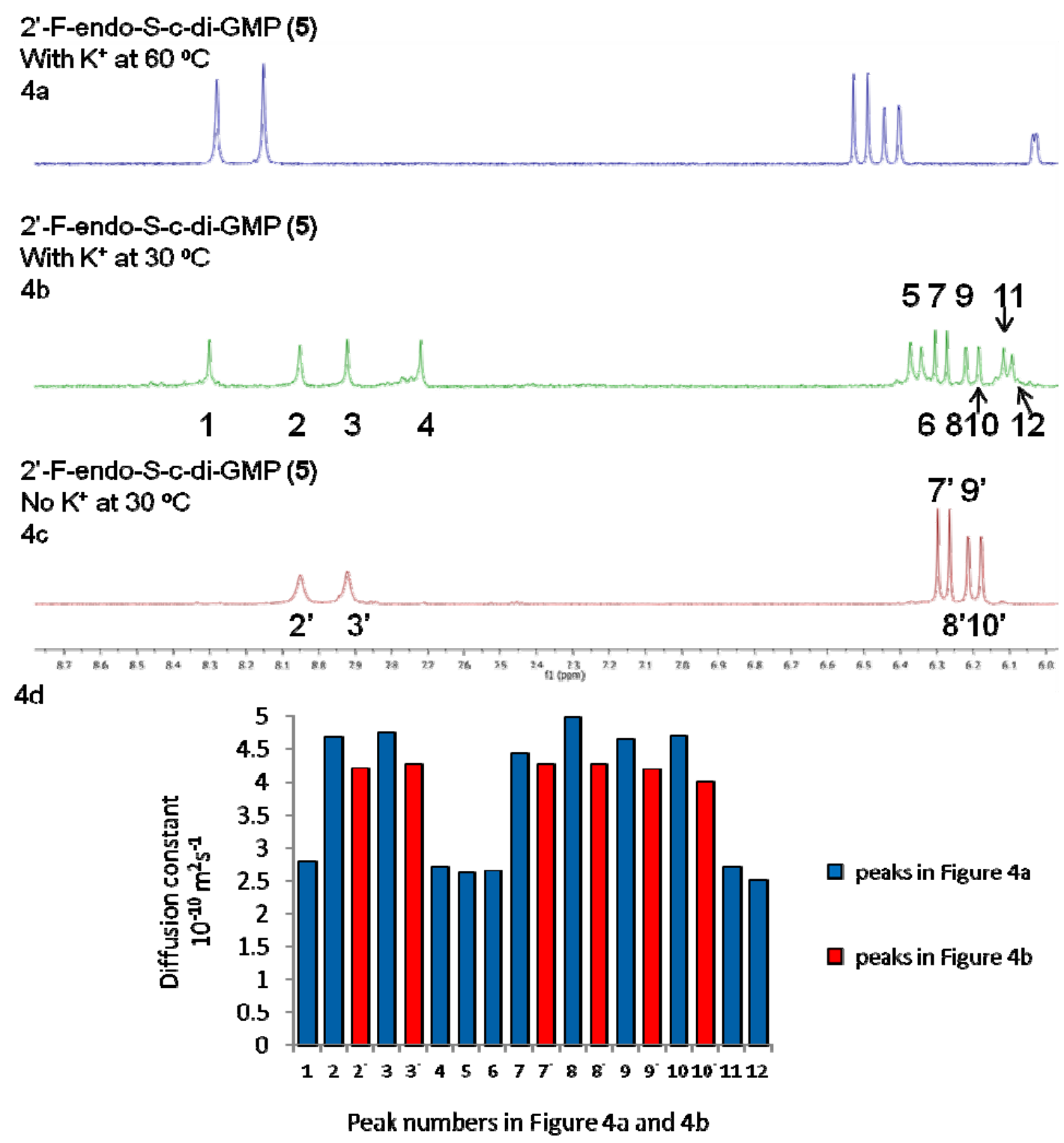

An alternative explanation could be that the line broadening is due to conformational heterogeneity (i.e., introduction of a fluorine atom at the 2' position changes the $\mathrm{C} 2$ '-endo or $\mathrm{C} 3$ '-endo equilibrium in the sugar ring, and the addition of $\mathrm{K}^{+}$ion changes this equilibrium rate). Upon adding $100 \mathrm{mM} \mathrm{K}^{+}$to a solution containing 2'-F-endo-S-c-di-GMP (5), more peaks appeared near $8.00 \mathrm{ppm}$ and $6.10 \mathrm{ppm}$, (see Figure 4b), which we interpret as evidence of aggregate formation [27]. Our interpretation is augmented by the fact that heating the solution to $60{ }^{\circ} \mathrm{C}$ resulted in the disappearance of the additional peaks, meaning that the new species that gave rise to the additional peaks contained non-covalent interactions. Additionally, DOSY experiments also confirmed that potassium promoted higher aggregation of 2'-F-endo-S-c-di-GMP; the new peaks (8.30 and 7.72 ppm, see peaks 1 and $\mathbf{4}$ on Figure 4b) that appeared in the 2'-F-endo-S-c-di-GMP ${ }^{1} \mathrm{H}-\mathrm{NMR}$, when potassium was added, have diffusion constants of $2.80 \times 10^{-10} \mathrm{~m}^{2} \mathrm{~s}^{-1}$ and $2.72 \times 10^{-10} \mathrm{~m}^{2} \mathrm{~s}^{-1}$, whereas the peak at 8.00 and $6.10 \mathrm{ppm}$ 
(see peaks 2 and 3 on Figure 4b) have diffusion constants $4.67 \times 10^{-10} \mathrm{~m}^{2} \mathrm{~s}^{-1}$ and $4.75 \times 10^{-10} \mathrm{~m}^{2} \mathrm{~s}^{-1}$. If peaks 2 and 3 mainly correspond to monomeric c-di-GMP with calculated radius of $6.82 \AA$, then the peaks at 1 and 4, which have experimental diffusion constants of $2.80 \times 10^{-10} \mathrm{~m}^{2} \mathrm{~s}^{-1}$ and $2.72 \times 10^{-10}$ $\mathrm{m}^{2} \mathrm{~s}^{-1}$ would correspond to a species of radius $11.60 \AA$. This radius is similar to the calculated radius (11.92 $\AA$ ) of octameric 2 '-F-endo-S-c-di-GMP and hence provides additional evidence that the addition of potassium to 2'-F-endo-S-c-di-GMP promotes aggregation into octameric forms.

We have previously shown that endo-S-c-di-GMP (2) does not readily form G-quadruplexes and commented that c-di-GMP G-quadruplex formation is sensitive to modifications (even conservative ones) [27]. Here we observe that a double modification (phosphate to phosphorothiolates and 2'-OH to $\left.2^{\prime}-\mathrm{F}\right)$ can restore the propensity to form higher aggregates, probably G-quadruplexes. Conversely, we found that for the other two double modifications investigated in this study (2'-H and 2'-OMe endo-S analogues), higher aggregates formation was suppressed.

\subsection{Binding of c-di-GMP and Analogues (2-5) to Vc2 c-di-GMP Riboswitch}

One of the motivations for making c-di-GMP analogues is to obtain small molecules that could have the potential to disrupt c-di-GMP signaling in bacteria. C-di-GMP has been shown to bind to several receptors types (both proteins and RNA) [27-33]. The crystal structures of c-di-GMP bound to both class I and II riboswitches have been solved [40-42]. For class I riboswitch, c-di-GMP is bound in the closed form (see Figure 5).

Figure 5. c-di-GMP fluorescent riboswitch. Sequence of RNA is, 5'-GAC GCG ACU GAA UGA AAU GGU GAA GGA CGG GUC CAG GC C GCA CAG GGC AAA CCA UUC GAA AGA GUG GGA CGC AAA GCC UCC GGC CUA AAC UUC GGU AGG UAG CGG GGU UAC CGA GC CUU GUU GAG UAG AGU GUG AGC UCC GUA ACU AGU CGC GUC-3'.

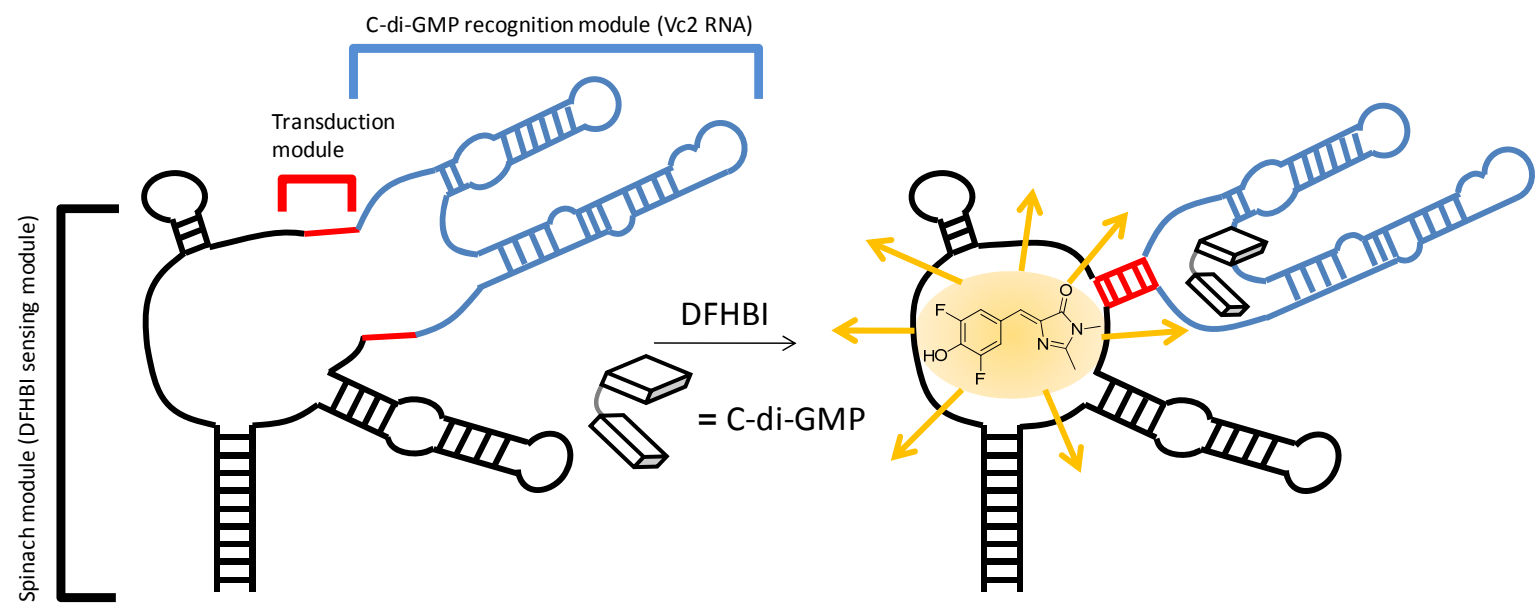

In a detailed study by Strobel and co-workers, it was demonstrated that substitution of the 2'-position of c-di-GMP was detrimental for binding to class I riboswitch, Vc2 RNA [28]. We have also revealed that the modification of the phosphate moiety of c-di-GMP decreased affinity for class I riboswitch Vc2 RNA [33], whereas binding to RocR (a phosphodiesterase) was not affected [27]. Therefore it might be possible to design c-di-GMP analogues that could selectively bind to one class of c-di-GMP receptor (for example proteins) and not others (for example RNA riboswitches). We 
investigated if the simultaneous modification of the phosphate and 2'-position of c-di-GMP would additively abrogate binding to the class I riboswitch. Several binding assays to investigate the binding of c-di-GMP and analogues to RNA receptors have been described, including competition with radio-labeled c-di-GMP [28], equilibrium microdialysis [33] and fluorescent c-di-GMP sensor, based on Vc2 RNA riboswitch (class I) [43] To gain a qualitative picture of the relative binding order of analogues, we opted to use the safer but qualitative fluorescent binding assay for c-di-GMP or analogue. The fluorescent c-di-GMP sensor would bind to c-di-GMP or analogue in the riboswitch binding site and the binding event is transduced to another domain, which rearranges to bind to DFHBI, a molecule that is weakly fluorescent in water but becomes highly fluorescent upon binding to RNA (called Spinach RNA). Using this class I riboswitch sensor, it was determined that the relative binding of c-di-GMP and analogues to class I riboswitch is as follows: c-di-GMP (1) > endo-S-c-di-GMP (2) > 2'-F-endo-Sc-di-GMP (5) > 2'-H- and 2'-OMe-endo-S-c-di-GMP (3 and 4), see Figure 6. We conclude that the modifications of the phosphate and 2'-position of c-di-GMP are additively detrimental to class I riboswitch binding. Curiously we note that this trend is also observed in the computed open:closed conformer ratio (Table 1). The computed energy differences between the various closed:open forms of c-di-GMP analogues $(\leq 2.2 \mathrm{kcal} / \mathrm{mol})$ is however too small, compared to the binding affinity of c-diGMP and the riboswitch ( $>30 \mathrm{kcal} / \mathrm{mol})$ so it is unlikely that the conformer distribution solely accounts for the differences seen in analogue binding to class I riboswitch.

Figure 6. Differential binding of endo-S-c-di-GMP analogues to fluorescent Vc2 RNA riboswitch [43]. Conditions: [RNA, SP_2] $=1 \mu \mathrm{M}$, [c-di-GMP and/or analogues] $=10 \mu \mathrm{M}$. Buffer: $100 \mathrm{mM}$ HEPES (pH 6.8) containing $100 \mathrm{mM} \mathrm{NaCl}, 100 \mathrm{mM} \mathrm{KCl}$ and $6 \mathrm{mM} \mathrm{MgCl}_{2}$.

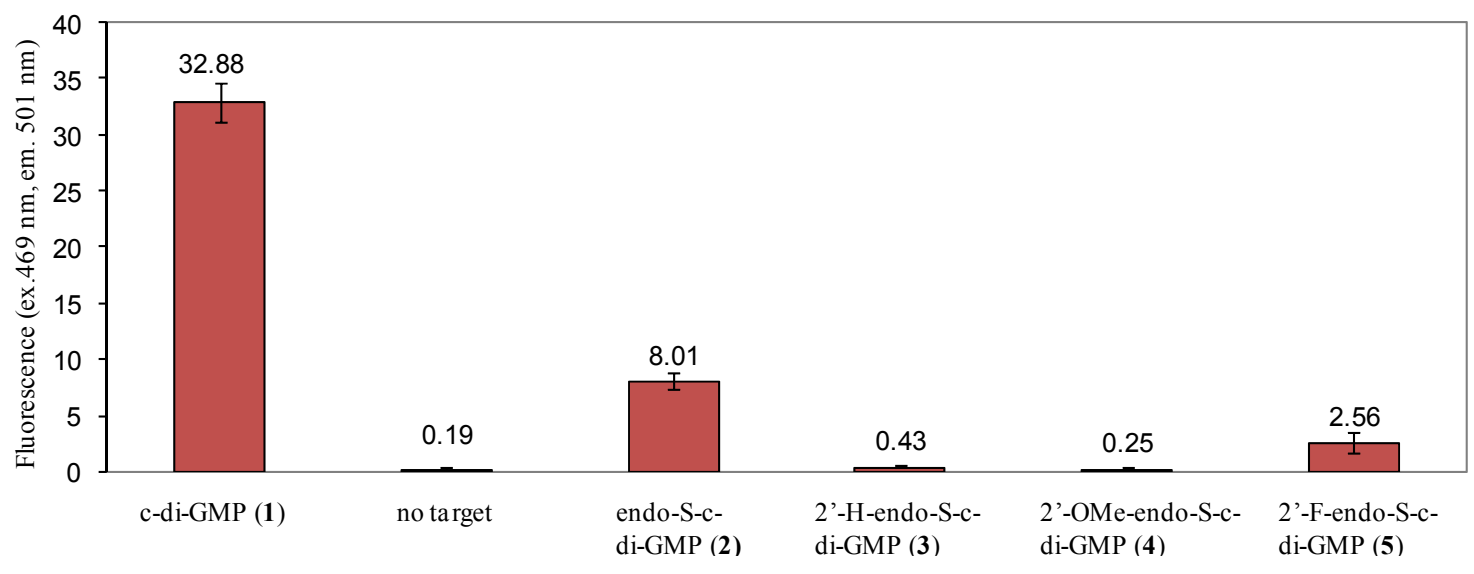

\section{Experimental}

\subsection{General}

Phosphoramidites used in the synthesis of c-di-GMP and analogues were purchased from ChemGenes. DNA/RNA synthesis grade acetonitrile, anhydrous pyridine, triethylamine and other chemicals used in the synthesis were purchased from Sigma-Aldrich (St. Louis, MO, USA) unless noted otherwise. NMR spectra were measured on a Bruker AVANCE II $600 \mathrm{MHz}$ spectrometer and UV absorbance spectra were obtained on a JASCO V-630 spectrophotometer using a $1 \mathrm{~cm}$ path length cuvette. The concentration of a stock solution of c-di-GMP and c-di-GMP analogues was determined 
by the measuring of the absorbance at $253 \mathrm{~nm}$ for c-di-GMP and c-di-GMP analogues, using $28,600 \mathrm{M}^{-1} \mathrm{~cm}^{-1}$ as a molar extinction coefficient for all compounds. Mass spectra were measured on a JEOL AccuTOF (Model \# JMS-T100CS, Tokyo, Japan) with ESI ion source. Dinucleotides were synthesized by Applied Biosystems 392 DNA/RNA synthesizer.

\subsection{Synthesis}

Sulfonylethyl-ODMT CPG (solid support, $10 \mu \mathrm{mol} / \mathrm{g}$ ) was prepared following literature [44]. It was loaded $(0.1 \mathrm{~g})$ into the synthesis columns and sealed tightly. A DNA/RNA synthesizer was used for making the dinucleotide. Two cycles of standard 1.0 $\mu$ mol RNA program were performed with an interruption before the oxidation step during the first cycle. In place of the oxidation step, a sulfurization step was performed using a solution of Beaucage reagent $(1 \mathrm{mg} / \mathrm{mL}$ in anhydrous acetonitrile, $1 \mathrm{~mL}$ ) for $30 \mathrm{~min}$. After the reaction was done, the synthesis columns were put back on to the DNA/RNA synthesizer for the rest of the synthesis cycles. The synthesis columns were then washed with anhydrous acetonitrile for another $60 \mathrm{~s}$ on the DNA/RNA synthesizer. The CPG beads were collected into round-bottom flask and further dried under the high vacuum for $5 \mathrm{~h}$ while gently stirring. Anhydrous DMF $(10 \mathrm{~mL})$ was then added to the flask, followed by a rapid transfer of methyltriphenoxyphosphonium iodide $(0.95 \mathrm{~g}, 2.10 \mathrm{mmol})$ and 2,6-lutidine $(1 \mathrm{~mL}, 8.61 \mathrm{mmol})$ under argon. The reaction was stirred for $1 \mathrm{~h}$ at RT before an aqueous solution of $\mathrm{Na}_{2} \mathrm{~S}_{2} \mathrm{O}_{3}(1 \mathrm{M}, 30 \mathrm{~mL})$ was poured into the reaction mixture. The CPG beads were washed with $\mathrm{H}_{2} \mathrm{O}(10 \mathrm{~mL} \times 3)$ and methanol $(10 \mathrm{~mL} \times 3)$ and stirred with ammonia $\left(30 \% \mathrm{NH}_{4} \mathrm{OH}\right.$ in water, $\left.15 \mathrm{~mL}\right)$ at $40{ }^{\circ} \mathrm{C}$ for $12 \mathrm{~h}$. The reaction mixture was then filtered and rinsed with $\mathrm{H}_{2} \mathrm{O}(10 \mathrm{~mL} \times 3)$. The combined filtrate was concentrated and for analogues (3-5), the crude products were directly subjected to HPLC purification (Nacalai tesque 5C18-PAQ column). HPLC condition: $1 \rightarrow 11 \% \mathrm{~B}, 0 \rightarrow 16 \min (\mathrm{A}: 0.1 \mathrm{M}$ TEAA (triethylammonium acetate) in water; $\mathrm{B}$ : acetonitrile). The fractions collected from HPLC were concentrated and washed with acetone $(2 \mathrm{~mL} \times 5)$ to remove the excess of TEAA buffer. $3-14 \mathrm{mg}$ products of analogues (3-5) were collected as white solid (estimated yields of $18-83 \%$ were obtained, based on the estimated loading of the CPG beads).

$2^{\prime}-H$-endo-S-c-di-GMP (3). ${ }^{1} \mathrm{H}-\mathrm{NMR}\left(500 \mathrm{MHz}, \mathrm{D}_{2} \mathrm{O}\right.$, water suppression, $\left.50{ }^{\circ} \mathrm{C}\right) \delta 8.26(\mathrm{~s}, 1 \mathrm{H}), 8.23$ (s, 1H), 6.65-6.43 (m, 2H), 5.41 (s, 2H), 4.69-4.48 (m, 2H), 4.46-4.27 (m, 2H), 3.33 (dd, J=13.3, 5.7 Hz, 2H), 3.23 (ddd, $J=20.6,13.3,6.1 \mathrm{~Hz}, 2 \mathrm{H}$ ), 3.02 (dt, $J=13.6,6.2 \mathrm{~Hz}, 1 \mathrm{H}), 2.92$ (ddd, $J=11.0,5.7,4.9 \mathrm{~Hz}$, 1H). ${ }^{31} \mathrm{P}-\mathrm{NMR}\left(202 \mathrm{MHz}, \mathrm{D}_{2} \mathrm{O}, 50{ }^{\circ} \mathrm{C}\right) \delta 19.7,-0.3$. ESI $/ \mathrm{MS}$ for $\left[\mathrm{C}_{20} \mathrm{H}_{23} \mathrm{~N}_{10} \mathrm{O}_{11} \mathrm{P}_{2} \mathrm{~S}\right]^{-}$: calculated 673.0749, Found: 673.0702.

2'-OMe-endo-S-c-di-GMP (4). ${ }^{1} \mathrm{H}-\mathrm{NMR}\left(500 \mathrm{MHz}, \mathrm{D}_{2} \mathrm{O}, 50{ }^{\circ} \mathrm{C}\right) \delta 8.31(\mathrm{~s}, 1 \mathrm{H}), 8.18(\mathrm{~s}, 1 \mathrm{H}), 6.30(\mathrm{~s}$, $1 \mathrm{H}), 6.19(\mathrm{~d}, J=4.5 \mathrm{~Hz}, 1 \mathrm{H}), 5.35(\mathrm{dt}, J=10.0,5.0 \mathrm{~Hz}, 1 \mathrm{H}), 5.21(\mathrm{td}, J=9.0,5.0 \mathrm{~Hz}, 1 \mathrm{H}), 4.91$ (t, $J=4.5 \mathrm{~Hz}, 1 \mathrm{H}), 4.66-4.52(\mathrm{~m}, 4 \mathrm{H}), 4.39-4.23(\mathrm{~m}, 1 \mathrm{H}), 3.87(\mathrm{~s}, 3 \mathrm{H}), 3.76(\mathrm{~s}, 3 \mathrm{H}), 3.52$ (ddd, $J=14.0,11.5,7.5 \mathrm{~Hz}, 1 \mathrm{H}), 3.32(\mathrm{ddd}, J=14.0,11.5,3.0 \mathrm{~Hz}, 1 \mathrm{H}) .{ }^{31} \mathrm{P}-\mathrm{NMR}\left(202 \mathrm{MHz}, \mathrm{D}_{2} \mathrm{O}, 50{ }^{\circ} \mathrm{C}\right)$ $\delta 18.9,-0.7 . \mathrm{ESI}^{-} / \mathrm{MS}$ for $\left[\mathrm{C}_{22} \mathrm{H}_{27} \mathrm{~N}_{10} \mathrm{O}_{13} \mathrm{P}_{2} \mathrm{~S}\right]^{-}$: calculated 733.0960, Found: 733.0981.

$2^{\prime}-F$-endo-S-c-di-GMP (5). ${ }^{1} \mathrm{H}-\mathrm{NMR}\left(500 \mathrm{MHz}, \mathrm{D}_{2} \mathrm{O}\right.$, water suppression, $\left.50{ }^{\circ} \mathrm{C}\right) \delta 8.28(\mathrm{~s}, 1 \mathrm{H}), 8.15$ (s, 1H), $6.51(\mathrm{~d}, J=19.0 \mathrm{~Hz}, 1 \mathrm{H}), 6.42(\mathrm{~d}, J=19.0 \mathrm{~Hz}, 1 \mathrm{H}), 5.98(\mathrm{dd}, J=52.0,3.5 \mathrm{~Hz}, 1 \mathrm{H}), 5.80$ (dd, 
$J=51.5,4.0 \mathrm{~Hz}, 1 \mathrm{H}), 5.50(\mathrm{tdd}, J=13.0,8.5,5.0 \mathrm{~Hz}, 1 \mathrm{H}), 5.35(\mathrm{dtd}, J=22.5,9.0,4.0 \mathrm{~Hz}, 1 \mathrm{H}), 4.63$ $(\mathrm{d}, J=12.5 \mathrm{~Hz}, 1 \mathrm{H}), 4.33(\mathrm{~d}, J=12.0 \mathrm{~Hz}, 1 \mathrm{H}), 3.69$ (dt, $J=13.5,5.0 \mathrm{~Hz}, 1 \mathrm{H}), 3.30(\mathrm{t}, J=11.0 \mathrm{~Hz}$, 1H). ${ }^{31} \mathrm{P}-\mathrm{NMR}\left(202 \mathrm{MHz}, \mathrm{D}_{2} \mathrm{O}, 50{ }^{\circ} \mathrm{C}\right) \delta 19.3,-0.5$. ESI $/ \mathrm{MS}$ for $\left[\mathrm{C}_{20} \mathrm{H}_{21} \mathrm{~F}_{2} \mathrm{~N}_{10} \mathrm{O}_{11} \mathrm{P}_{2} \mathrm{~S}\right]^{-}$: calculated 709.0561, Found: 709.0596.

\subsection{Sample Preparation for Spectrometric Measurements}

C-di-GMP or c-di-GMP analogues, water, and metal solution were mixed, heated to $95{ }^{\circ} \mathrm{C}$ and kept at $95{ }^{\circ} \mathrm{C}$ for $5 \mathrm{~min}$, cooled back to room temperature for $15 \mathrm{~min}$, then incubated in a refrigerator for $12 \mathrm{~h}$.

\subsection{DOSY NMR Experiments and $T_{1} / T_{2}$ Relaxation Analysis}

The Bruker AVANCE II $600 \mathrm{MHz}$ spectrometer was used to determine diffusion constants. Shigemi NMR tubes $\left(\mathrm{D}_{2} \mathrm{O}\right)$ were used for all experiments. DOSY was measured with the stimulated echo pulse sequence (Bruker pulse program stebpgp1s19) using bipolar gradient pulses and watergate 3-9-19 to suppress the solvent. Key acquisition parameters for the DOSY experiment include the big delta (4) at $0.09 \mathrm{~s}$, the number of scans at 32, relaxation delay at $2.5 \mathrm{~s}$, and the gradient strength was varied 32 times linearly from 5 to $95 \%$. The gradient pulse length (small delta $\delta$ ) within the range of 1.4-1.8 ms was optimized under the experiment conditions until the region of 6.0-9.0 ppm showed good decays for the major peaks. The data were processed with TopSpin 2.1 software with $T_{1} / T_{2}$ relaxation analysis. Exponential function was applied for the raw data and the curve-fitting of the decays was based on the area of the peaks.

\subsection{Sample Preparation of Fluorescence Measurement}

C-di-GMP or analogues and DFHBI concentrations were determined via UV absorbance measurements (c-di-GMP at $253 \mathrm{~nm}$ and DFHBI at $405 \mathrm{~nm}$ ) and 28,600 $\mathrm{M}^{-1} \mathrm{~cm}^{-1}$ (c-di-GMP), $11,864 \mathrm{M}^{-1} \mathrm{~cm}^{-1}$ (DFHBI) were used as extinction coefficients to calculate concentrations. RNA in buffer solution was heated to $80{ }^{\circ} \mathrm{C}$ for $5 \mathrm{~min}$ and cooled down to room temperature in $15 \mathrm{~min}$. Then $\mathrm{MgCl}_{2}$ and c-di-GMP were added and the sample was kept for $12 \mathrm{~h}$ at room temperature.

\subsection{Fluorescence Measurement}

DFHBI was added to samples and fluorescence was monitored by excitation at $496 \mathrm{~nm}$ and emission at $501 \mathrm{~nm}$.

\section{Conclusions}

In conclusion, we reveal that by modifying both the phosphate and 2'-positions of c-di-GMP, one could arrive at analogues that show differential biophysical (conformational steering [27]) and biochemical properties. Replacement of one of the oxygen atoms in phosphodiesters can affect both structure and the enzymatic processing of these phosphorothiolate analogues. Usually, it is assumed that the replacement of the exocyclic oxygen with sulfur is less conservative than replacing the endocyclic bridging oxygen. Herein, we reinforce that even a presumed conservative change to the 
endocyclic oxygen in c-di-GMP can have profound effects in both the property of the nucleotide and binding to receptors [27].

\section{Acknowledgments}

This work was supported by National Science Foundation (CHE0746446 to HOS), Camille Dreyfus Foundation (HOS) and American Heart Association (11PRE7890040 fellowship to JZ). We thank our group members, Shizuka Nakayama and Yiling Luo for help with the transcription of c-di-GMP fluorescent riboswitch.

\section{References and Notes}

1. Ross, P.; Weinhouse, H.; Aloni, Y.; Michaeli, D.; Weinberger-Ohana, P.; Mayer, R.; Braun, S.; de Vroom, E.; van der Marel, G.A.; van Boom, H.H.; et al. Regulation of cellulose synthesis in Acetobacter xylinum by cyclic diguanylic acid. Nature 1987, 325, 279-281.

2. Römling, U.; Gomelsky, M.; Galperin, M.Y. C-di-GMP: The dawning of a novel bacterial signalling system. Mol. Microbiol. 2005, 57, 629-639.

3. Sondermann, H.; Shikuma, N.J.; Yildiz, F.H. You've come a long way: C-di-GMP signaling. Curr. Opin. Microbiol. 2012, 15, 140-146.

4. Ryan, R.P.; Tolker-Nielsen, T.; Dow, J.M. When the PilZ don't work: Effectors for cyclic di-GMP action in bacteria. Trends Microbiol. 2012, 20, 235-242.

5. Krasteva, P.V.; Giqlio, K.M.; Sondermann, H. Sensing the messenger: The diverse ways that bacteria signal through c-di-GMP. Protein Sci. 2012, 21, 929-948.

6. Römling, U. Cyclic di-GMP, an established secondary messenger still speeding up. Environ. Microbiol. 2012, 14, 1817-1829.

7. Chan, C.; Paul, R.; Samoray, D.; Amiot, N.C.; Giese, B.; Jenal, U.; Schirmer, T. Structural basis of activity and allosteric control of diguanylate cyclase. Proc. Natl. Acad. Sci. USA 2004, 101, 17084-17089.

8. Yang, C.Y.; Chin, K.H.; Chuah, M.L.; Liang, Z.X.; Wang, A.H.; Chou, S.H. The structure and inhibition of a GGDEF diguanylate cyclase complexed with (c-di-GMP) $)_{2}$ at the active site. Acta Crystallogr. D Biol. Crystallogr. 2011, 67, 997-1008.

9. Minasov, G.; Padavattan, S.; Shuvalova, L.; Brunzelle, J.S.; Miller, D.J.; Baslé, A.; Massa, C.; Collart, F.R.; Schirmer, T.; Anderson, W.F. Crystal structures of YkuI and its complex with second messenger cyclic di-GMP suggest catalytic mechanism of phosphodiester bond cleavage by EAL domains. J. Biol. Chem. 2009, 284, 13174-13184.

10. Tchigvintsev, A.; Xu, X.; Singer, A.; Chang, C.; Brown, G.; Proudfoot, M.; Cui, H.; Flick, R.; Anderson, W.F.; Joachimiak, A.; et al. Structural insight into the mechanism of c-di-GMP hydrolysis by EAL domain phosphodiesterases. J. Mol. Biol. 2010, 402, 524-538.

11. Ko, J.; Ryu, K.S.; Kim, H.; Shin, J.S.; Lee, J.O.; Cheong, C.; Choi, B.S. Structure of PP4397 reveals the molecular basis for different c-di-GMP binding modes by Pilz domain proteins. J. Mol. Biol. 2010, 398, 97-110.

12. Benach, J.; Swaminathan, S.S.; Tamayo, R.; Handelman, S.K.; Folta-Stogniew, E.; Ramos, J.E.; Forouhar, F.; Neely, H.; Seetharaman, J.; Camilli, A.; et al. The structural basis of cyclic diguanylate signal transduction by PilZ domains. EMBO J. 2007, 26, 5153-5166. 
13. Habazettl, J.; Allan, M.G.; Jenal, U.; Grzesiek, S. Solution structure of the PilZ domain protein PA4608 complex with cyclic di-GMP identifies charge clustering as molecular readout. J. Biol. Chem. 2011, 286, 14304-14314.

14. Hickman, J.W.; Harwood, C.S. Identification of FleQ from Pseudomonas aeruginosa as a c-di-GMP-responsive transcription factor. Mol. Microbiol. 2008, 69, 376-389.

15. Baraquet, C.; Murakami, K.; Parsek, M.R.; Harwood, C.S. The FleQ protein from Pseudomonas aeruginosa functions as both a repressor and an activator to control gene expression from the pel operon promoter in response to c-di-GMP. Nucleic Acids Res. 2012, 40, 7207-7218.

16. Sudarsan, N.; Lee, E.R.; Weinberg, Z.; Moy, R.H.; Kim, J.N.; Link, K.H.; Breaker, R.R. Riboswitches in eubacteria sense the second messenger cyclic di-GMP. Science 2008, 321, 411-413.

17. Smith, K.D.; Shanahan, C.A.; Moore, E.L.; Simon, A.C.; Strobel, S.A. Structural basis of differential ligand recognition by two classes of bis-(3'-5')-cyclic dimeric guanosine monophosphate-binding riboswitches. Proc. Natl. Acad. Sci. USA 2011, 108, 7757-7762.

18. Cheek, M.A.; Dobrikov, M.I.; Wennefors, C.K.; Xu, Z.; Hashmi, S.N.; Shen, X.; Shaw, B.R. Synthesis and properties of (alpha-P-borano)-nucleoside 5'-triphosphate analogues as potential antiviral agents. Nucleic Acids Symp. Ser. (Oxf.) 2008, 52, 81-82.

19. Wennefors, C.K.; Dobrikov, M.I.; Xu, Z.; Li, P.; Shaw, B.R. Stereospecificity, substrate, and inhibitory properties of nucleoside diphosphate analogs for creatine and pyruvate kinases. Bioorg. Chem. 2008, 36, 169-177.

20. Hamm, M.L.; Cholera, R.; Hoey, C.L.; Gill, T.J. Oligonucleotide incorporation of 8-thio-2'-deoxyguanosine. Org. Lett. 2004, 6, 3817-3820.

21. Hamm, M.L.; Gill, T.J.; Nicolson, S.C.; Summers, M.R. Substrate specificity of Fpg (MutM) and hOGG1, two repair glycosylases. J. Am. Chem. Soc. 2007, 129, 7724-7725.

22. Wauchope, O.R.; Johnson, C.; Krishnamoorthy, P.; Andrei, G.; Snoeck, R.; Balzarini, J.; Seley-Radtke, K.L. Synthesis and biological evaluation of a series of thieno-expanded tricyclic purine 2'-deoxy nucleoside analogues. Bioorg. Med. Chem. 2012, 20, 3009-3015.

23. Novikov, M.S.; Ivanova, O.N.; Ivanov, A.V.; Ozerov, A.A.; Valuev-Elliston, V.T.; Temburnikar, K.; Gurskaya, G.V.; Kochetkov, S.N.; Pannecouque, C.; Balzarini, J.; et al. 1-[2-(2-Benzoyl- and 2-benzylphenoxy)ethyl]uracils as potent anti-HIV-1 agents. Bioorg. Med. Chem. 2011, 19, 5794-5802.

24. Cassera, M.B.; Zhang, Y.; Hazleton, K.Z.; Schramm, V.L. Purine and pyrimidine pathways as targets in Plasmodium falciparum. Curr. Top. Med. Chem. 2011, 11, 2103-2115.

25. Chemama, M.; Fonvielle, M.; Villet, R.; Arthur, M.; Valéry, J.M.; Etheve-Quelquejeu, M. Stable analogues of aminoacyl-tRNA for inhibition of an essential step of bacterial cell-wall synthesis. J. Am. Chem. Soc. 2007, 129, 12642-12643.

26. Shukla, S.; Sumaria, C.S.; Pradeepkumar, P.I. Exploring chemical modifications for siRNA therapeutics: A structural and functional outlook. ChemMedChem 2010, 5, 328-349.

27. Wang, J.; Zhou, J.; Donaldson, G.P.; Nakayama, S.; Yan, L.; Lam, Y.F.; Lee, V.T.; Sintim, H.O. Conservative change to the phosphate moiety of cyclic diguanylic monophosphate remarkably affects its polymorphism and ability to bind DGC, PDE, and PilZ proteins. J. Am. Chem. Soc. 2011, 133, 9320-9330.

28. Shanahan, C.A.; Gaffney, B.L.; Jones, R.A.; Strobel, S.A. Differential analogue binding by two classes of c-di-GMP riboswitches. J. Am. Chem. Soc. 2011, 133, 15578-15592. 
29. Smith, K.D.; Strobel, S.A. Interactions of the c-di-GMP riboswitch with its second messenger ligand. Biochem. Soc. Trans. 2011, 39, 647-651.

30. Furukawa, K.; Gu, H.; Sudarsan, N.; Hayakawa, Y.; Hyodo, M.; Breaker, R.R. Identification of ligand analogues that control c-di-GMP riboswitches. ACS Chem. Biol. 2012, 7, 1436-1443.

31. Ching, S.M.; Tan, W.J.; Chua, K.L.; Lam, Y. Synthesis of cyclic di-nucleotidic acids as potential inhibitors targeting diguanylate cyclase. Bioorg. Med. Chem. 2010, 18, 6657-6665.

32. Sharma, I.M.; Dhanaraman, T.; Mathew, R.; Chatterji, D. Synthesis and characterization of a fluorescent analogue of cyclic di-GMP. Biochemistry 2012, 51, 5443-5453.

33. Luo, Y.; Zhou, J.; Watt, S.K.; Lee, V.T.; Dayie, T.K.; Sintim, H.O. Differential binding of 2'-biotinylated analogs of c-di-GMP with c-di-GMP riboswitches and binding proteins. Mol. Biosyst. 2012, 8, 772-778.

34. Smietana, M.; Kool, E.T. Efficient and simple solid-phase synthesis of short cyclic oligodeoxynucleotides bearing a phosphorothioate linkage. Angew. Chem. Int. Ed. Engl. 2002, 41, 3704-3707.

35. Chin, K.H.; Kuo, W.T.; Yu, Y.J.; Liao, Y.T.; Yang, M.T.; Chou, S.H. Structural polymorphism of c-di-GMP bound to an EAL domain and in complex with a type II PilZ-domain protein. Acta Crystallogr. D Biol. Crystallogr. 2012, 68, 1380-1392.

36. Zhang, Z.; Kim, S.; Gaffney, B.L.; Jones, R.A. Polymorphism of the signaling molecule c-di-GMP. J. Am. Chem. Soc. 2006, 128, 7015-7024.

37. Zhang, Z.; Gaffney, B.L.; Jones, R.A. C-di-GMP displays a monovalent metal ion-dependent polymorphism. J. Am. Chem. Soc. 2004, 126, 16700-16701.

38. Gaussian 09, Revision A02; Software for technical computation; Gaussian Inc.: Wallingford, CT, USA, 2009.

39. Gentner, M.; Allan, M.G.; Zaehringer, F.; Schirmer, T.; Grzesiek, S. Oligomer formation of the bacterial second messenger c-di-GMP: Reaction rates and equilibrium constants indicate a monomeric state at physiological concentrations. J. Am. Chem. Soc. 2012, 134, 1019-1029.

40. Kulshina, N.; Baird, N.J.; Ferré-D’Amaré, A.R. Recognition of the bacterial second messenger cyclic diguanylate by its cognate riboswitch. Nat. Struct. Mol. Biol. 2009, 16, 1212-1217.

41. Smith, K.D.; Lipchock, S.V.; Ames, T.D.; Wang, J.; Breaker, R.R.; Strobel, S.A. Structural basis of ligand binding by a c-di-GMP riboswitch. Nat. Struct. Mol. Biol. 2009, 16, 1218-1223.

42. Smith, K.D.; Lipchock, S.V.; Livingston, A.L.; Shanahan, C.A.; Strobel, S.A. Structural and biochemical determinants of ligand binding by the c-di-GMP riboswitch. Biochemistry 2010, 49, 7351-7359.

43. Nakayama, S.; Luo, Y.; Zhou, J.; Dayie, T.K.; Sintim, H.O. Nanomolar fluorescent detection of c-di-GMP using a modular aptamer strategy. Chem. Commun. (Camb.) 2012, 48, 9059-9061.

44. Patnaik, S.; Kumar, P.; Garg, B.S.; Gandhi, R.P.; Gupta, K.C. Photomodulation of PS-modified oligonucleotides containing azobenzene substituent at pre-selected positions in phosphate backbone. Bioorg. Med. Chem. 2007, 15, 7840-7849.

Sample Availability: Samples of the materials are available from the authors.

(C) 2012 by the authors; licensee MDPI, Basel, Switzerland. This article is an open access article distributed under the terms and conditions of the Creative Commons Attribution license (http://creativecommons.org/licenses/by/3.0/). 